\title{
PRESENTACIÓN: HISTÓRICAS. MOVIMIENTOS FEMINISTAS Y DE MUJERES EN CHILE, 1850-2020
}

\author{
Ana María Carrasco Gutiérrez*
}

Agradezco a la Red de Historiadoras Feministas (RHF) haberme otorgado el privilegio de presentar el libro Históricas. Movimientos feministas y de mujeres en Chile, 1850-2020, el que considero una aportación inédita al conocimiento acerca de los movimientos de mujeres en Chile, instancias que, tal como sus autoras lo expresan, han dado "cuerpo y fuerza a las organizaciones políticas feministas que nacerían en Chile durante los siglos XX y XXI". De ahí que valoro la materialización de esta publicación.

Son, sin dudas, muchos los aportes que podemos señalar de esta obra, conformada por 4 capítulos que dan cuenta de, ni más ni menos, 170 años de historia; de los que solo mencionaré y me centraré en dos contribuciones que, desde mi punto de vista, son centrales.

La primera de ella es que, mediante sus contenidos, se renueva la crítica a la historia excluyente de las mujeres; se refuerza el rechazo al esencialismo biológico como explicación de la desigualdad entre los sexos y se reafirma el poder de los discursos en la construcción social de la diferencia sexual.

No hay que olvidar que aun cuando hoy existe consenso que la historia de las mujeres resulta tanto o más rica en acontecimientos que la historia de los hombres, es solo en décadas recientes que se empieza a advertir, en la historiografía nacional, un real interés por la descentralización del sujeto masculino y posteriormente del sujeto unitario mujer (Luna, L. 2004:22).

Durante siglos la Historia Oficial ha tenido como principal referente las actividades desarrolladas por "los hombres", al adjudicarle a esta categoría la universalidad de la especie humana. Esta dimensión patriarcal y "unidimensional" de las ciencias (utilizando el concepto de Lerner, G. 1990:20), con la que por mucho tiempo ha sido analizado el pasado y que aún es visible sobre todo en las ciencias sociales y en particular en la disciplina histórica, evidencia la invisibilidad en que se nos coloca a las mujeres en sociedades como la nuestra, especialmente de la vida pública u oficial. Nosotras, durante siglos, no hemos sido consideradas actrices de este devenir, hemos representado solo personajes secundarios y marginales, hemos sido siempre privadas de toda identidad autoconstruida e invisibilizadas de los anales de cualquier historia (Carrasco AM. 2018:26).

Por definición, la historia debe ser la ciencia que permita a la Humanidad conocer, aproximarse o palpar su pasado, su presente y su futuro; debe permitirnos estar en contacto directo con lo que éramos, con lo que somos y, si se quiere, con lo que seremos. Pero esto no siempre ha sido así. Hay grupos, sectores sociales, personajes, discriminados de su propia historia y las mujeres somos uno de ellos. Si bien hoy existe consenso de que somos sujetas activas de la realidad social, es solo recientemente que este reconocimiento es aceptado por la historia.

Ahora, sin lugar a duda, las autoras de este libro se incluyen entre las investigadoras que buscan cambiar estos defectos disciplinarios. Esto, porque sus escritos nos revelan una visión más globalizadora, problemática y verdadera de nuestra historia, mostrándonos el largo camino de lucha y participación social y política de las mujeres chilenas, aquel que por mucho tiempo fue ocultado tras la mirada androcéntrica, que ha invisibilizado la existencia y fuerza de estos movimientos.

Como segundo aporte, me gustaría dar cuenta de los casi dos siglos de movimientos sociales-políticos de mujeres en Chile que nos presenta el texto. Para ello Históricas nos entrega, documentadamente, una muy completa síntesis del movimiento de mujeres y feministas; cuestión no fácil, si consideramos que estamos hablando de presentar el desarrollo histórico de uno de los movimientos sociales, activo y vigente, de más larga duración en la historia de Chile.

\footnotetext{
* Departamento de Antropología, Universidad de Tarapacá, Arica, Chile.

Correo electrónico: anycarrasco@gmail.com, amcarrasco@uta.cl
} 
El texto sistematiza magistralmente lo que ha sido el movimiento de mujeres en Chile, retomando y analizando aquellos datos que generalmente encontramos parcelados, poniendo énfasis en el desarrollo histórico que ha tenido la formación de la conciencia feminista, revisando las diversas expresiones y demandas formuladas en diversos periodos históricos e incorporando y conjugando en la lectura, variables como género, clase y etnia que, sin dudas, están presentes dentro del movimiento de mujeres y que habitualmente se excluyen.

Históricas nos presenta la trayectoria participativa femenina por medio de varias etapas por las que ha atravesado el movimiento de mujeres, haciéndonos poner atención a los aspectos políticos que estas variadas formas de expresión colectivas contienen. Desde la lucha por los derechos de ciudadanía, por la subsistencia, por los derechos humanos, contra la dictadura, por la democracia, hasta sus acciones contra las discriminaciones de género que, en las últimas décadas, se expresan fuertemente en los movimientos de mujeres, feministas y de las disidencias sexuales.

Sin dudas, el texto que hoy presento contribuye a abrir el conocimiento de nuestra verdadera historia aportando con dilucidar y profundizar el significado político de las actuaciones de las mujeres en los movimientos sociales. Movimientos de mujeres que en su diversidad recorren América Latina y nuestro país, desde finales del siglo XIX y se desarrollan en profundidad a lo largo de la primera ola en la primera mitad del siglo XX; de la segunda ola, en la segunda mitad del mismo siglo; $y$, recientemente, de la nueva ola feminista (tercera ola) de mujeres jóvenes cuyas voces se alzan, continúan, profundizan y expanden por el país y el mundo.

Así como nos lo muestra Históricas, las mujeres chilenas han tenido y tienen un largo historial de lucha y participación social y política. Esta característica que arranca desde principios del siglo pasado ha continuado hasta hoy con su fuerte presencia en distintas instancias organizativas, lo que pone de manifiesto las formas de organización e incorporación de las mujeres en la política, por medio de los movimientos de mujeres, caracterizados por su diversidad y heterogeneidad; visibilizándose acciones colectivas que han logrado provocar un cambio social en la relación de poder entre las mujeres y el Estado; develando acciones que sin dudas contribuyen a dar a luz aspectos desconocidos y no reconocidos de nuestro pasado que ayudan a explicar y fortalecer nuestro presente.

Presente que en el libro se plasma abordando los últimos desarrollos de los movimientos de mujeres, feministas y LGBTQ+, producidos durante las últimas décadas y que forman parte de esta larga historia que el movimiento de mujeres tiene. Historia, con momentos de visibilidad y momentos de latencia; pero siempre con una continuidad importante de demandas femeninas.

Hoy con un movimiento feminista que sale a las calles, convirtiéndose en un movimiento de masas que se revela contra la violencia patriarcal en sentido amplio y que se expresa de muchas y distintas maneras: como violación, como acoso, como maltrato, como asesinato, como desigualdad económica y laboral, etc. Movimiento con nuevas generaciones de mujeres conscientes de sus diferencias y particularidades que no pretenden homogenizar el movimiento (Gilmore 1997:218), sino por el contrario, logran exaltar la diversidad, sea esta cultural, social, religiosa, racial, sexual y que han sido capaces de decir a quienes quieran escuchar: NO es NO, poniendo en el centro simbólico de la sociedad y como significante, la necesidad de justicia para las mujeres.

Finalizo compartiendo con ustedes una cita de J. Kirkwood que creo cierra perfectamente esta presentación:
“... la recuperación de la historia propia de opresión y contestación de todo un colectivo de mujeres permitirá satisfacer la necesidad de que las generaciones presentes de mu- jeres conozcan su propio pasado real, con vistas a que su inserción futura no tienda, nuevamente, a la negación de sí mismas y a la reafirmación de su no-identidad" (J. Kirkwood,1987:25).

Y esto se consigue con acciones concretas como las que la Red de Historiadoras Feministas nos ha regalado mediante su notable obra: Históricas. Movimientos feministas y de mujeres en Chile, 1850-2020. 


\section{Referencias Citadas}

\section{Carrasco, A.M}

2006 Hacia un nuevo significado de la política: Los movimientos de mujeres en la región de Tarapacá, Chile (1910-1973). Ediciones Universidad de Tarapacá, Arica, Chile.

Gilmore, S

2001 "Looking Back, Thinking Ahead: Third Wave Feminism in the United States", en Journal of Women's History, 12 , Indiana University Press, invierno, pp. 215-221.
Kirkwood, J.

1987 Feminarios. Documentas, Santiago, Chile.

Lerner, G.

1990 La creación del patriarcado. Editorial Crítica, Barcelona, España.

Luna, L.

2004 El sujeto sufragista. Feminismo y feminidad en Colombia: 1930-1957. Ediciones La Manzana de la Discordia/ Centro de Estudios de Género, Mujer y Sociedad/ Universidad del Valle. 